\title{
Profile of acute poisoning cases presenting to health centres and hospitals in Oman
}

S.B. Lall, ${ }^{1}$ S.S. Al-Wahaibi, ${ }^{1}$ M.M. Al-Riyami, ${ }^{1}$ and K. Al-Kharusi ${ }^{1}$

$$
\begin{aligned}
& \text { مُرتَتَمَ حالات التسمُّم الحاد في المراكز الصحية والمستشفيات في عُمان }
\end{aligned}
$$

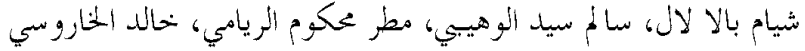

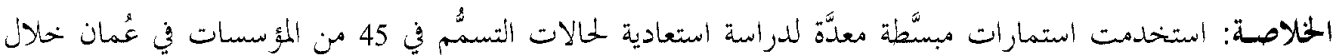

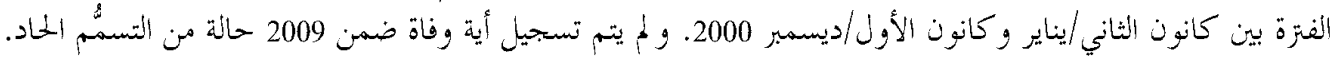

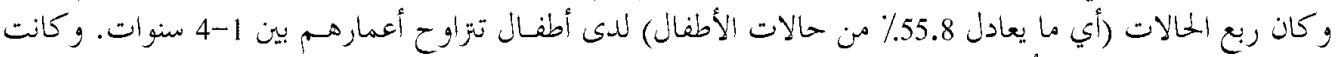

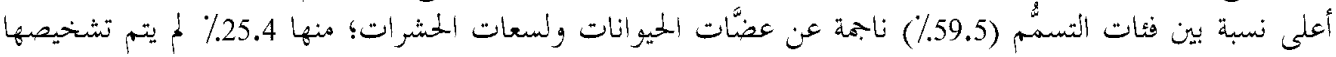

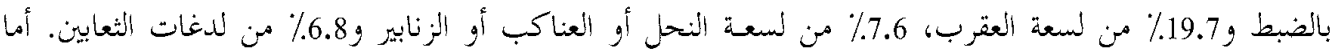

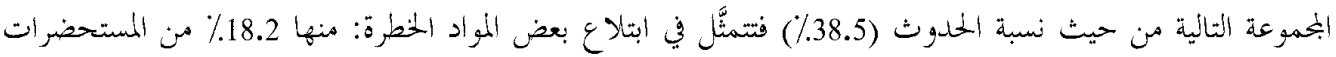

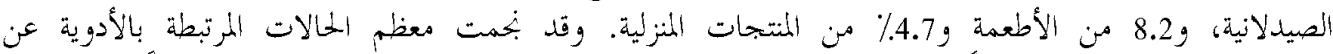

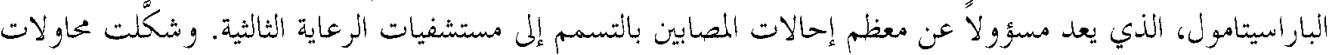

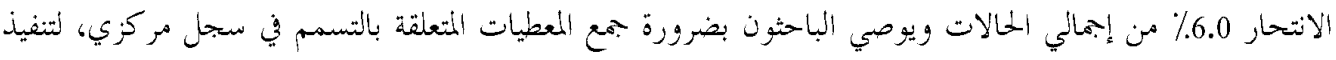

$$
\text { برامج وقائية في المستقبل وتقييمها. }
$$

ABSTRACT A simple pro forma was used for a retrospective study of poisoning cases at 45 health institutions in Oman during January-December 2000. No deaths were recorded among 2009 cases of acute poisoning. A quarter of all cases (55.8\% of paediatric cases) were children aged $1-4$ years. The largest category (59.5\%) was animal bites and stings: $25.4 \%$ undiagnosed, $19.7 \%$ scorpion stings, $7.6 \%$ bee, spider or wasp stings and $6.8 \%$ snake bites. Next highest (38.5\%) was ingestion of substances: $18.2 \%$ pharmaceuticals, $8.2 \%$ food and $4.7 \%$ household products. Most drug-related cases were due to paracetamol. Suicide attempts were recorded for $6.0 \%$. Collection of poisoning data through a central registry system is needed for the implementation and future assessment of prevention programmes.

Profil des cas d'intoxication aiguë se présentant dans les centres de santé et les hôpitaux à Oman RESUME Un simple formulaire type a été utilisé pour une étude rétrospective des cas d'intoxication dans 45 établissements de santé à Oman de janvier à décembre 2000. Aucun décès n'a été enregistré parmi les 2009 cas d'intoxication aiguë. Un quart de tous les cas ( $55,8 \%$ des cas pédiatriques) concernait des enfants âgés de 1-4 ans. La catégorie la plus importante (59,5\%) était celle des morsures d'animaux et des piqûres : non diagnostiquées $25,4 \%$, piqûres de scorpions $19,7 \%$, piqûres d'abeilles, d'araignées ou de guêpes $7,6 \%$ et morsures de serpents $6,8 \%$. La catégorie qui venait tout de suite après (38,5\%) était l'ingestion de substances : produits pharmaceutiques $18,2 \%$, denrées alimentaires $8,2 \%$ et produits ménagers $4,7 \%$. La plupart des cas d'intoxication associée à des médicaments étaient dus au paracétamol. Les tentatives de suicide concernaient $6,0 \%$ des cas. Le recueil de données sur les intoxications au moyen d'un système de registre central est nécessaire pour la mise en œuvre de programmes de prévention et leur évaluation future.

${ }^{1}$ Directorate of Environmental Health and Malaria Eradication, Ministry of Health, Muscat, Oman. Received: 23/09/01; accepted: 08/01/02 


\section{Introduction}

Poisoning is an important health problem in every country of the world. Occupational exposure to industrial chemicals and pesticides, accidental or intentional exposure to household and pharmaceutical products and poisoning due to venomous animals, toxic plants and food contamination, all contribute to morbidity and mortality. However, the magnitude of the problem, the circumstances of exposure and the types of poisoning vary from country to country. The variables include the degree of industrialization and urbanization, the type of agricultural activities and the available medical facilities and expertise to prevent and manage toxic exposures.

The health impact of chemical exposures and poisoning is well recognized in most industrialized countries, where chemical safety and poison control programmes are established. The Toxic Exposure Surveillance System (TESS) data, compiled by the American Association of Poison Control Centers, for example, provides evidence about toxic exposures and subsequent health effects throughout the United States, and is utilized to identify emerging hazards, to focus prevention and education programmes and to guide clinical research and training [1]. In contrast, most developing countries have not yet fully recognized the risks posed by chemicals on human health and the environment. One reason is the lack of sound national epidemiological data on toxic exposures and poisoning. Some case studies and hospital-based retrospective and prospective studies have documented poisoning-related morbidity and mortality and the changing trend of chemical exposures [2-6]. However, such data remain insufficient to guide decision-makers in developing preventive and management strategies at country level.
The Sultanate of Oman, with a population of 2.4 million, has undergone a rapid economic growth in the last 3 decades, with diversification from an oil-based economy to other industries, agriculture and fishing. In the process, more chemicals and commercial products are being imported and used, thus exposing the population to the increased risk of occupational, accidental and intentional poisoning. This is in addition to the existing risks of poisoning from venomous animals, food contamination, pharmaceuticals and traditional remedies. The data on clinical case registration, compiled in the Ministry of Health (MOH) based on the ICD-10 system, shows significant morbidity due to poisoning and toxic exposures in every region of the country [7]. However, the current system of data collection is inadequate to provide complete epidemiological information. As poisoning is classified with injuries, the data accounts only for accidental exposures. There is no information on the circumstances of exposure, type of chemicals involved and severity of poisoning. A large number of exposures are due to unknown substances. The data do not allow for an assessment of the available diagnostic and treatment facilities and expertise at each health care level.

In view of the high incidence and morbidity due to toxic exposures and growing risk of chemical accidents and environmental contamination in Oman, the country plans to initiate chemical safety and poison control programmes. Sound epidemiological data on the toxic risks is essential for planning the activities of the poison control centre in a rational way. This 1-year retrospective study of poisoning cases was conducted to generate necessary data to help in evidence-based decision-making related to

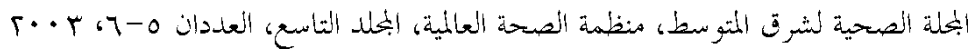


prevention and management of toxic exposures and poisoning in Oman.

\section{Methods}

The Sultanate of Oman is administratively divided into 10 health regions with 59 wilayat. Each health region has an upgraded regional hospital and an office of the Directorate General of Health Services to strengthen decentralization of health services. Each region provides primary, secondary and tertiary health care to the population, through primary health centres, extended health centres and secondary and tertiary care hospitals. Four MOH referral hospitals catering to different specialties are located in Muscat, where patients are referred from the regional hospitals. Each wilayat hospital provides health services to about $30000-50000$ people in the region. They have 10-20 inpatient beds with polyclinic facilities. These hospitals are well connected to the regional hospitals for referral and administration. The local hospitals have more bed strength and extended facilities than wilayat hospitals. Extended health centres (6/114 health centres) provide 24 -hour polyclinic facilities.

The director general of each region was contacted by phone and informed about the aims and objectives of the study and their role in the project. The pro formas were then faxed to the regional office, and further faxed to various health centres and hospitals in the region to supply the necessary information. The follow-up and collection of pro formas was carried out by representative health workers or sanitary inspectors from each region.

Forty-five health institutions were selected to cover primary, secondary and tertiary levels: $4 \mathrm{MOH}$ referral hospitals in Muscat (Royal Hospital, Khoula Hospital,
Al Nahdha Hospital and Ibn Sina Hospital), 7 regional hospitals, 3 wilayat hospitals, 16 local hospitals, 10 health centres, 3 extended health centres, and 2 other non-MOH referral hospitals (Sultan Qaboos University Hospital and the Armed Forces Hospital).

A simple 1-page database pro forma was prepared to collect information about each poisoning case treated at each institution during the period January-December 2000. The parameters included in the pro forma were: name of the patient, age, sex, type of poison, mode and route of exposure, time since exposure, management outside hospital, presenting symptoms, examination, investigations, treatment and outcome.

The medical officers of all the hospitals were contacted by telephone and were informed about the aims and objectives of the study, their role and responsibility in the project and about the various terms used in the pro forma. In addition, representative health workers or sanitary inspectors from all 10 regions of the country were invited to the Directorate of Environmental Health and Malaria Eradication and were briefed about the importance of data collection and the terms used in the pro forma. These workers helped in the follow-up and collection of pro formas. Representatives at the Royal (the main general referral hospital), Sultan Qaboos and the Armed Forces hospitals were personally contacted and briefed about the study before the pro forma was handed over. A time period of 3 months was allotted for sending back the completed pro formas. When there was no response or incomplete information reminders were sent.

The pro formas received from individual hospitals were analysed and the data was then computed to provide region-wide and nationwide information on the incidence of 
poisoning, age and sex of patients, mode and route of exposure, regional variations, and the expertise and facilities available for managing poisoning cases at each health care level.

\section{Results}

\section{Data from primary and secondary health care levels}

Of 45 health institutions included in the study, 40 sent data about poisoning cases, while 5 reported having no poisoning cases during the study period. Data from 2 hospitals and 1 extended health centre $(n=513$ cases) were excluded because of incomplete information. Analysis of the data was made on a total of 2009 poisoning cases during the year.

The age distribution was analysed among the 1569 poisoning cases where the patient's age was specified (440 sheets coded 'A' for adults were excluded). Of these cases, 867 (55.3\%) were adolescents and adults aged 13-76 years and 702 (44.7\%) children aged 6 months-12 years
(Figure 1). Further analysis showed poisoning between the ages 1-4 years constituted $55.8 \%$ of the paediatric cases. More of the cases were male than female (936:633, a M:F ratio of $1.5: 1$ ), especially among children (445:257). Due to lack of information about the occupation and address of the patients in the submitted pro formas, the rate of poisoning in relation to socioeconomic status, occupational exposure or rural/urban residence, could not be analysed.

The route of exposure was skin contact from bites/stings from venomous animals or insects in $59.5 \%$ of the 2009 cases or ingestion of substances in $38.5 \%$. The route of exposure remained unknown in 41 cases $(2.0 \%)$ (Table 1$)$. Ingestion of substances was recorded as accidental for $32.0 \%$, and intentional (suicidal attempts) for $6.0 \%$.

Poisoning was categorized into 10 types, based on the ICD-10 with slight modifications. The largest category was poisoning due to unknown animal or insect bites (25.4\%), followed by scorpion stings

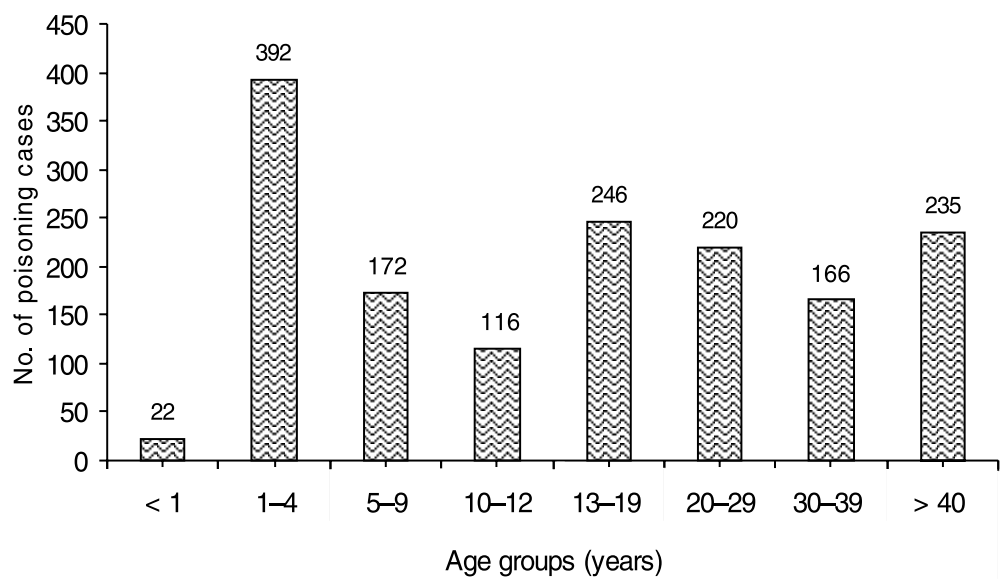

Figure 1 Age distribution of 1569 poisoning cases

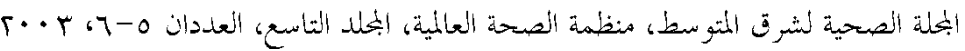


(19.7\%) and ingestion of pharmaceutical substances (18.2\%) (Table 1). Pesticide poisoning was rare $(1.9 \%)$.

Analysis by age showed that the maximum number of poisonings in adults were for unknown insect bites and stings (30.0\%) and scorpion stings (26.0\%). The highest proportion of poisonings in children were due to ingestion of pharmaceutical substances (27.0\%), whereas only $13.5 \%$ of adult cases were due to pharmaceuticals. Of the paediatric cases, food poisoning was recorded in $12.0 \%$, exposure to household products in $8.5 \%$ and kerosene in $7.0 \%$, compared with $5.5 \%, 2.5 \%$, and $0.2 \%$ respectively in adults.

The incidence and types of poisonings varied across the 10 regions (Table 1 ). However, similar types of poisoning cases presented at primary and secondary health care levels in each region, suggesting a role for geographical and climatic factors. For example, the highest incidence of snakebites was recorded in Dhofar region
(26.5\% of all snakebites) and poisoning due to scorpion stings was extremely high in Dhahirah (63.9\% of scorpion stings). Muscat region had the highest number of cases due to poisoning from pharmaceuticals (41.4\% of pharmaceutical exposures) and household products (36.2\% of household exposures). Insect bites categorized as 'unknown animal/insect bite' were greatest in North Batinah region (52.4\% of all unknown bites).

\section{Data from referral hospitals}

The Royal Hospital and Sultan Qaboos University Hospital sent complete data on all poisoning cases admitted: 159 and 65 respectively. The other national referral hospitals either had no poisoning cases or a few cases that were computed with the national data reported above.

More of the cases admitted to the Royal Hospital were children than the University Hospital (Table 2): 43\% versus 26\% in the age $1-4$ years, all accidental poisonings.

\begin{tabular}{|c|c|c|c|c|}
\hline \multirow[t]{2}{*}{ Variable } & \multicolumn{2}{|c|}{ Royal Hospital $(n=159)$} & \multicolumn{2}{|c|}{$\begin{array}{c}\text { Sultan Qaboos University } \\
\text { Hospital }(n=65)\end{array}$} \\
\hline & No. & $\%$ & No. & $\%$ \\
\hline \multicolumn{5}{|l|}{ Sex } \\
\hline Male & 91 & 57 & 32 & 49 \\
\hline Female & 68 & 43 & 33 & 51 \\
\hline \multicolumn{5}{|l|}{ Age group (years) } \\
\hline Adults $>13$ & 68 & 43 & 43 & 66 \\
\hline Children $<1-13$ & 91 & 57 & 22 & 34 \\
\hline Children 1-4 & 69 & 43 & 17 & 26 \\
\hline \multicolumn{5}{|l|}{ Type of poisoning } \\
\hline $\begin{array}{l}\text { Ingestion of pharmaceuticals } \\
\text { Ingestion of pesticide/kerosene/ }\end{array}$ & 100 & 63 & 40 & 62 \\
\hline household and industrial products & 36 & 23 & 16 & 25 \\
\hline Bites/stings/other & 23 & 14 & 9 & 14 \\
\hline
\end{tabular}

$\mathrm{n}=$ total number of poisoning cases.

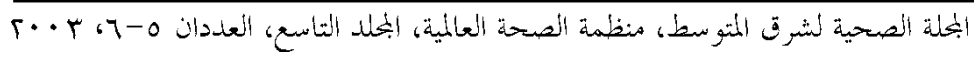


Adult poisonings due to pharmaceuticals were the most common category in both hospitals: 63\% in the Royal Hospital and $62 \%$ in the University Hospital. Most of these cases were suicide attempts (80\% in the Royal, 90\% in the University Hospital)

The types of drug poisoning in these hospitals are shown in Table 3. Paracetamol poisoning was the most frequent category of drug poisoning with the 30 cases constituting $21 \%$ of total pharmaceutical poisonings $(n=140)$. Of these 30 cases, 14 were children and 16 were adults.

\section{Treatment and outcome}

Data about the treatment and outcome of poisoning cases suggested that the diagnostic and treatment facilities at primary care level are inadequate. Primary care centres reported administering anti-snake ven-

Table 3 Pharmaceutical products ingested by poisoning cases treated at 2 referral hospitals in Oman

\begin{tabular}{|c|c|c|c|c|}
\hline \multirow[t]{2}{*}{$\begin{array}{l}\text { Pharmaceutical } \\
\text { product }\end{array}$} & \multicolumn{2}{|c|}{$\begin{array}{l}\text { Royal Hospital } \\
\quad(n=100)\end{array}$} & \multicolumn{2}{|c|}{$\begin{array}{c}\text { Sultan Qaboos University } \\
\text { Hospital }(n=40)\end{array}$} \\
\hline & No. & $\%$ & No. & $\%$ \\
\hline Paracetamol & 18 & 18 & 12 & 30 \\
\hline Other NSAID & 13 & 13 & 0 & \\
\hline Antidepressant & 6 & 6 & 3 & 8 \\
\hline Antipsychotic & 0 & 0 & 2 & 5 \\
\hline Antiepileptic & 5 & 5 & 4 & 10 \\
\hline Anti-anxiety & 3 & 3 & 2 & 5 \\
\hline Opioids & 3 & 3 & 0 & 0 \\
\hline Antihypertensive & 7 & 7 & 0 & 0 \\
\hline$\beta$-agonist & 2 & 2 & 0 & 0 \\
\hline Anticoagulant & 1 & 1 & 0 & 0 \\
\hline Antitussive & 2 & 2 & 0 & 0 \\
\hline Antidiabetic & 1 & 1 & 1 & 3 \\
\hline Anti-allergic & 6 & 6 & 3 & 8 \\
\hline Antispasmodic & 3 & 3 & 1 & 3 \\
\hline Antibiotic & 2 & 2 & 2 & 5 \\
\hline Hormone & 5 & 5 & 0 & 0 \\
\hline Tonic & 6 & 6 & 0 & 0 \\
\hline Iron & 4 & 4 & 6 & 15 \\
\hline Purgative & 3 & 3 & 0 & 0 \\
\hline Skin cream & 4 & 4 & 0 & 0 \\
\hline Combined & 1 & 1 & 3 & 8 \\
\hline Unknown & 5 & 5 & 1 & 0 \\
\hline
\end{tabular}

$\mathrm{n}=$ total number of pharmaceutical poisoning cases.

$N S A I D=$ non-steroidal anti-inflammatory drug.

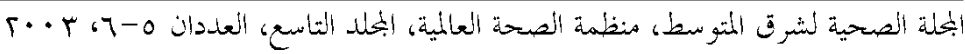


om and hydrocortisone injections in $90 \%$ of the snakebite cases even in the absence of systemic symptoms and positive laboratory findings. Though coagulation profiling was done at some centres, renal function tests were rarely done. The scorpion sting cases were treated by local infiltration of xylocaine and oral administration of antihistamines and analgesics. Blood pressure was rarely measured in these cases. Undiagnosed cases of insect bites were treated as scorpion stings.

Gastric lavage was carried out at both primary and secondary care levels for all cases of gastric poisoning, including kerosene ingestion. Activated charcoal and antidotes were usually not available at primary care level. Most of the drug and pesticide poisonings presenting to primary care facilities were referred to secondary level hospitals, indicating inadequate facilities and expertise to manage these patients. Nevertheless, initial supportive care facilities are available in primary care. The secondary level hospitals have antidotes such as naloxone, atropine, pralidoxime (2-PAM) and activated charcoal; however, the facilities for monitoring blood levels of drugs and some of the important antidotes such as $\mathrm{N}$-acetyl cysteine are not available.

No poisoning-related deaths were recorded in any of the hospitals or health centres over the 1-year period of the study.

Information from the Royal and University Hospitals suggest that the experience and facilities to manage poisoning cases are adequate in both referral hospitals.

\section{Discussion}

Acute poisoning is an important clinical emergency and contributor to morbidity and mortality [8]. Early diagnosis, treatment and prevention is crucial in reducing the burden of poisoning-related injury in any country. Baseline epidemiological data depicting the susceptible groups in the community, high-risk circumstances, toxic risks, and the availability of diagnostic and treatment facilities are essential to evolve strategies for strengthening poisoning prevention and management at all health care levels. The present study was undertaken to generate such data for planning poison control activities in Oman.

The study recorded 2009 cases of acute poisoning treated at primary, secondary and tertiary health care institutions during a 1 -year period. The number is close to the number of inpatient cases of poisoning (2342) recorded by the Omani $\mathrm{MOH}$ in the same year [7]. However, since not all institutions participated in the study and some were excluded for not submitting complete information, our data does not depict the actual countrywide incidence, which would in fact be much higher. Moreover, poisoning cases treated as outpatients were not accounted for, as complete records were not available. The national health statistics showed the number of outpatients treated for poisoning in the same year was 9646 [7]; these data are also unreliable as there was overlap between inpatient and outpatient numbers, a sampling method was used for outpatient data collection and poisoning was classified with injuries. Nevertheless, all the data indicates that poisoning and toxic exposures are a significant health problem in this country. Furthermore, non-availability of records and incomplete information about the cases suggests the need for harmonized data sheets for collection of poisoning data through a central registry system, from inpatient, outpatient and emergency departments of all hospitals and health centres in the country.

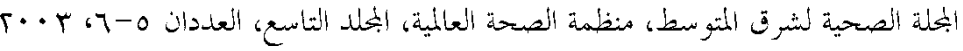


Interestingly, there were no poisoningrelated deaths among the 2009 inpatient cases in our study. The national health statistics recorded only 8 deaths from poisoning during the year, 7 of whom were drug abusers [7]. Such low mortality indicates good supportive care and quick referral to tertiary care hospitals. This is apparent from the records of the 2 referral hospitals. A report from one of these hospitals showed that there were no deaths in 1999; however, high morbidity was indicated by $78 \%$ of the poisoning cases admitted for 110 days occupying a total of 134 bed days with an average lodging cost of US\$ 5550 excluding medical care costs [9]. A recent 4-year prospective hospital-based study from Sultan Qaboos University Hospital revealed that $73 \%$ of poisoning cases were admitted to hospital, for periods ranging from 1-175 days, further confirming the high poisoning-related morbidity in this country [10]. The only comparable nationwide hospital data available in the literature is from Sri Lanka for the year 1994, where total hospital admissions and deaths due to poisoning were 55079 and 2283 respectively. The very high mortality (4\%) in Sri Lanka was due to pesticide poisoning [11].

Our results further revealed that $44.7 \%$ of the poisonings involved children below 12 years of age and that children aged 1-4 years were the most vulnerable to accidental exposures. The results are in accordance with hospital-based reports from other countries [5,9,12,13]. A recent study from the United States of America showed that children under 5 years of age had a significantly higher average annual rate of poisoning-related visits to emergency departments than other age group [8].

Among adolescents and adults, the highest frequency of poisoning was in the age range 13-19 years; however, attempted suicide by poisoning was not common in the sample overall (6.0\%). This contrasts with studies from south-east Asian countries where the highest rates of intentional poisoning $(60 \%-82 \%)$ were in adults $[4,10,14]$.

In our study, male cases of poisoning outnumbered females, among both adults and children, as has been observed by others $[5,9,13]$. However, a 12-year study from the UK [15], and short-term retrospective studies from Iran [16] and Turkey [17] reported more cases of acute poisoning in females.

Our data showed that $59.5 \%$ of the poisoning cases overall were due to bites and stings and nearly half of these cases were categorized as 'unknown animal/insect bite'. The highest proportion of undiagnosed stings and bites (52.4\% and 18.4\% of unknown bites respectively) were from 2 regions: North Batinah and Dakhliya. Since most of these cases were treated as scorpion stings, lack of proper diagnosis was probably responsible for such high figures. The most common known category of poisoning was scorpion stings (19.7\% of poisoning cases), and these were most common in the desert region of Dhahirah.

The next most common category of poisoning was ingestion of pharmaceuticals (18.2\%) and these were highest in the Muscat region. The inpatient data of the 2 referral hospitals in Muscat showed the highest proportion of admissions were due to ingestion of pharmaceutical agents (63\%, 62\%). A similar high percentage of drug poisoning (62\%) was reported in recent retrospective studies from referral hospitals in Tehran [16] and China [18]. Our data further indicated that the total number of pharmaceutical exposures was higher in children $(27.0 \%)$ than in adults (13.5\%). This could be due to a number of factors: the non-availability of childproof containers in this country; unsafe storage 
of medicines in the home; the free and easy access to medicines from the government that leads to hoarding; and lastly the lack of awareness of parents about use of drugs. Paracetamol poisoning was the most frequent category in children as well as in adults. This is in accordance with some other reports $[10,16]$. The reasons might be that it is one of the most common drugs available in households and that treatment facilities at the health centres are inadequate to manage these patients. In Asian countries, however, paracetamol poisoning is reported infrequently among children $[13,20,21]$, who more often suffer from kerosene and food poisoning [4,13].

Pesticide poisoning is lowest category of poisoning in Oman $(1.9 \%$ of total cases). It could be due to misdiagnosis of accidental exposures since the incidence of suicides by poisoning in our study was low and was mostly due to pharmaceutical rather than pesticide ingestion. This is in contrast to the high incidence of pesticide poisoning recorded in some Asian countries $[2,4,5]$.
That there were no deaths due to acute poisoning at tertiary health care level clearly indicates that the management facilities for toxic exposures are adequate. However, unnecessary referrals, morbidity and health care cost could be reduced if the facilities and expertise are strengthened at primary and secondary health care level. Training programmes for health professionals to update knowledge and practice in diagnosis and treatment are needed. Due to regional differences in the incidence of poisoning, these should be tailored to regional needs. Prevention programmes for reducing accidental exposures to pharmaceuticals and household product, especially in children, are required in some regions.

\section{Acknowledgements}

We thank Mr A.M. Al-Kasmi, the Director of Information and Statistics at the Ministry of Health, the medical officers and the pharmacies at participating health institutions for providing us with the data for the study.

\section{References}

1. American Association of Poison Control Centres. Annual report 1999. Washington DC, AAPCC, 1999.

2. Fernando R. Pesticide poisoning in Asia Pacific Region and the role of a regional information network. Journal of toxicology, clinical toxicology, 1995, 33:67782.

3. Chopra JS et al. Aluminium phosphate: a prospective study of 16 cases in one year. Postgraduate medical journal, 1986, 62:1113-15.

4. Thomas $\mathrm{M}$ et al. Profile of hospital admissions following acute poisoning: experi- ence from a teaching hospital in South India. Adverse drug reactions and toxicological reviews, 2001, 19:313-7.

5. Lall SB, Peshin SS, Seth SD. Acute poisonings: a ten year retrospective hospital-based study. Annals of the National Academy of Medical Sciences, 1994, 30:35-44.

6. Singh $S$ et al. Changing patterns of acute poisoning in adults: Experience at a large north-west Indian hospital. Journal of the Association of Physicians of India, 1997, 45:194-7.

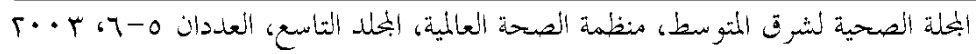


7. Ministry of Health, Sultanate of Oman. Annual statistical report 2000. Muscat, Directorate General of Planning, 2001.

8. McCaig LF, Burt CW et al. Poisoningrelated visits to emergency departments in the United States. Journal of toxicology, clinical toxicology, 1999, 37:81726.

9. Hanssens $Y$ et al. Poisoning cases reported at Sultan Qaboos University Hospital over 1999. Pharmacy bulletin, 2000, 6:6.

10. Hanssens $Y$, Deleu D, Taqi A. Etiologic and demographic characteristics of poisoning: a prospective hospital-based study in Oman. Journal of toxicology, clinical toxicology, 2001, 39:371-80.

11. Fernando R. Poisons centre in Sri Lanka: highlights and experiences. In: Lall SB, ed. Essentials of clinical toxicology. New Delhi, Narosa Publishing House, 1998: 275-9.

12. Mahdi AH, Taha SA, Al-Rifai MR. Epidemiology of accidental home poisoning in Riyadh (Saudi Arabia). Journal of epidemiology and community health, 1983, 37:291-5.

13. Datta AK et al. Poisoning in children: Indian scenario. Indian journal of pediatrics, 1998, 65:365-70.

14. Dewan A. Experience at poisons information centre at $\mathrm{NIOH}$, Ahmenabad. In:
Lall SB, ed. Essentials of clinical toxicology. New Delhi, Narosa Publishing House, 1998:280-4.

15. Lawson AA, Mitchell I. Patients with acute poisoning in a general medical unit (1960-71). British medical journal, 1972, 4:153-6.

16. Abdollahi $\mathrm{M}$ et al. A retrospective study of poisoning in Tehran. Journal of toxicology, clinical toxicology, 1997, 35:38793.

17. Ozkose Z, Ayoglu F. Etiological and demographical characteristics of acute adult poisoning in Ankara, Turkey. $\mathrm{Hu}$ man \& experimental toxicology, 1999, 18:614-8.

18. Liu Y, Wolf LR, Zhu W. Epidemiology of adult poisoning at China Medical University. Journal of toxicology, clinical toxicology, 1997, 35:175-80.

19. Hawton K et al. Paracetamol self poisoning. Characteristics, prevention and harm reduction. British journal of psychiatry, 1996, 168:43-8.

20. Lall SB, Paul R. Paracetamol poisoning in children. Indian journal of pediatrics, 1998, 65:393-400.

21. Yang CC et al. Children poisoning in Taiwan. Indian journal of pediatrics, 1997, 64:469-83. 